\title{
Visiones distintas acerca del valor de la cultura: explorando las partes malditas
}

\author{
Different views about the value of culture: \\ exploring the cursed shares
}

\author{
Jorge Fernández León \\ Fundación Municipal de Cultura, Educación y Universidad Popular \\ Ayuntamiento de Gijón
}

\section{Resumen}

Una buena parte de la literatura económica especializada aborda una interpretación del valor de la cultura centrada en su consideración de mercancía. Pero hay quienes, sin negar esa interpretación, se acercan a él como valor de uso y por sus virtudes sociales y su condición más allá de su medida; otros defienden una clasificación más centrada en sus valores como derechos ciudadanos; otros acuden a distintas teorías del valor para analizar la función de los productos culturales en la sociedad actual; incluso desde la ortodoxia económica para el análisis de procesos y productos culturales, existe una diversidad de aproximaciones. Recogemos y comentamos aqui algunas de esas visiones.

Palabras clave: valor de la cultura, economía de la cultura, derechos culturales, cultura como mercancía, bienes de valor social, lo sublime, índice de felicidad.

Clasificación JEL: Z10.

\begin{abstract}
Much of the specialized economic literature addresses an interpretation of the values of culture centered on its commodity function. But there are also those scholars who, without wholly rejecting it, propose an approach based on use values and theorize about their social virtues and their condition beyond its measure; other academics defend a vision more focused on those values as citizen rights; others turn to diverse value theories to analyze the role of cultural products in contemporary society. Even within the field of economic orthodoxy for the measurable determination of cultural processes and products, there is a diversity of approaches. We collect and comment here some of those views.
\end{abstract}

Keywords: cultural value, cultural economics, cultural rights, culture as commodity, public goods, the sublime, happiness index.

JEL classification: Z10.

NOTA: En el artículo se utilizan numerosas citas de publicaciones de las que no disponemos de versión en español. Las traducciones para facilitar el seguimiento de los argumentos son responsabilidad exclusiva del autor.

DOI: https://doi.org/10.32796/cice.2019.98.6953 


\section{Introducción}

La investigación económica aplicada en el campo de la cultura es una disciplina relativamente joven. Nacida en el mundo anglosajón hace algo más de medio siglo a partir sobre todo del libro seminal de Baumol y Bowen (1966), ha generado un cuerpo de profesionales dedicado a su exploración desde una interpretación frecuentemente microeconómica del valor de la cultura centrada en el valor monetario de sus productos, dejando sitio escaso a otras visiones distintas. Y lo ha hecho muchas veces renunciando a comprender el sentido de los procesos creativos más allá de su función de mercancías. Como ambos autores establecen en la introducción del texto:

No pretendemos descubrir una panacea que prometa curar a las artes de sus males financieros. Más bien esperábamos ser capaces de especificar objetivamente las alternativas que han de afrontar las artes y describir los costes y las cargas que estas reclaman a la sociedad que soporte (p. 5).

El corolario de las tesis del libro se describe en la literatura del sector como «la enfermedad de Baumol» y el argumento es concluyente: podemos considerar no solo que la cultura es una mercancía más, sino que está enferma del mal del gasto y que, por tanto, en el sentido político del término, estamos hablando de una «carga» para la sociedad, cuyo origen y condiciones pretenden debatir y analizar.

La idea de situar el valor de la cultura como una «enfermedad» ${ }^{1}$ (que coincidirá, como contrapunto en la distancia, con las teorías de Foucault (2009) en torno a la aparición de la biopolítica ${ }^{2}$ ) es una forma de entender el campo de la cultura como un mal, necesario, pero no necesariamente beneficioso para la comunidad, que ha de ser tratado en el campo de las políticas del cuerpo y, por tanto, formar parte de las tareas que deben ser asumidas por el Estado para su regulación. Así lo proponen Baumol y Bowen (1966) en su libro, frente a las percepciones críticas respecto a la cultura y sus valores generadas por el pensamiento de la Escuela de Frankfurt (Adorno, 1991; Benjamin, 2008) y sus sucesores en el campo de los estudios culturales ${ }^{3}$ o de la sociología y el pensamiento crítico francés, especialmente el de Bourdieu (1988). Otros economistas, sin embargo, al examinar la función de la cultura en la sociedad y el papel del Estado en su regulación, mantienen tesis distintas que queremos resaltar. Y recordar someramente algunos de sus planteamientos ocupa la primera parte de este trabajo. Porque

\footnotetext{
${ }^{1}$ Una visión interesante del uso del término «enfermedad» la encontramos en un texto del profesor Hans Abbing, en un artículo no publicado, recuperado de http://www.hansabbing.nl/DOCeconomist/Let's\%20 forget $\% 20$ about $\% 20$ cost $\% 20$ disease $\% 20$ A5\%20version $\% 20060702$.pdf

2 Michel Foucault, en una conferencia en octubre de 1974 en la Universidad Estatal de Río de Janeiro, plantea que «El control de la sociedad sobre los individuos no solo se efectúa mediante la conciencia o por la ideología, sino también en el cuerpo y con el cuerpo. Para la sociedad capitalista es lo bio-político lo que importa, ante todo, lo biológico, lo somático, lo corporal. El cuerpo es una entidad biopolítica, la medicina es una estrategia biopolítica». Recuperado de https://es.wikipedia.org/wiki/Biopol\%C3\%ADtica.

${ }^{3}$ Para conocer en detalle la historia y relevancia de los estudios culturales -una disciplina presente en la mayoría de las Universidades del mundo anglosajón- así como sus controversias, puede consultarse el detallado estudio de Simon During (2005), Cultural Studies: a Critical Introduction. London: Routledge.
} 
son el Estado, junto con la sociedad y el mercado, las tres patas que permiten abordar un análisis del valor de la cultura más allá de lo unidimensional (McGuigan, 2004).

Se examinan aquí, en el primer apartado tras esta introducción, las miradas de la economía especializada sobre el valor de la cultura, dedicándose, a continuación, un apartado específico a quienes, desde ese campo, la relacionan de maneras muy distintas con el bienestar personal y social. En el apartado cuarto, se aborda la interpretación de Bataille (1967), el autor que de forma más audaz propone una nueva economía general basada en una noción de gasto radicalmente distinta, para después, en la quinta parte, resumir algunas ideas en torno a la filosofía de lo sublime (del Pseudo-Longino ${ }^{4}$ a Lyotard, 1984). En el sexto bloque se abordan los trabajos sobre el valor de la cultura de pensadores como Sloterdijk (2002), Groys (2005, 2008), Eagleton (2001, 2017), García Canclini (2010), Ordine (2013), o Belfiore (2018), que nos proponen distintas taxonomías del mismo. La parte descriptiva se cierra con un séptimo bloque en torno a la importancia central del valor de la cultura como derecho y un octavo apartado que presenta el distinto panorama del valor de la cultura hoy para los gobiernos de la Unión Europea y los Estados Unidos. Finaliza el artículo con algunas conclusiones y recomendaciones.

\section{La economía especializada}

Entre los cientos de autores posibles, para presentar un panorama plural de la investigación aplicada, se han seleccionado textos de economistas desde la década de los ochenta -Cummings y Katz (1987), Dubin (1987), Grampp (1989), Gortz (1989), Miege (1989), Heilbrun y Gray (1993), Klamer (1996), Caves (2000), Throsby (2001 y 2010), Towse $(2005,2010)$ y, de forma singular, por su actualidad, Frey (2002, 2008, 2018)-, que abordan, de maneras más o menos restrictivas, el asunto de los valores de la cultura y el peso de la razón económica en el análisis de la realidad social. Miradas que se mueven entre la visión de la economía neoclásica, que sigue teniendo a Baumol y Bowen como referencia y nuevas formas de comprender la complejidad del valor, más allá de la materialidad de la mercancía. No se menciona la obra de otros autores de prestigio (Mark Blaug, Victor Ginzburgh o Alan Peacock, por ejemplo) puesto que sus ideas centrales quedan reflejadas en las de muchos de los representados en el artículo.

Milton R. Cummings Jr. y Richard S. Katz (1987) señalan los factores que determinan el peso cambiante de la posición financiera de la cultura y las artes, presentes en las políticas públicas en Estados Unidos desde fines del siglo XIX gracias a las presiones de las grandes fortunas para establecer mecanismos de desgravación

${ }^{4}$ Pseudo-Longino o Longino. Se conoce por este y otros nombres, de certeza dudosa, al autor del tratado De lo Sublime, en el que se fijan principios de construcción del discurso, teoría poética y estética de lo sublime. Escrito entre los siglos I y II es citado como fuente por numerosos teóricos de filosofía e historia de la estética desde el siglo XVIII en Europa (Kant, Schiller, Burke, Schopenhauer, etc.) hasta nuestros días, en que aparece de nuevo a partir de un texto de J. F. Lyotard. 
fiscal y a sus intereses personales de prestigio ${ }^{5}$. El estudio abarca desde la crisis de las políticas públicas culturales tras la I Guerra Mundial, debido al crecimiento de las tasas e impuestos públicos destinados a abordar las gravísimas desigualdades sociales generadas por el pago de la deuda de guerra, hasta su florecimiento tras la II Guerra Mundial como parte de las políticas del bienestar. Cummings, en su examen de las políticas culturales de 13 Estados, señala la importancia de determinar factores de valoración de la cultura, que «Dentro de cada campo de las artes, permita elegir entre la conservación del patrimonio cultural y el estímulo de los nuevos esfuerzos creativos» (p. 14). En un trabajo posterior, Cummings y Schuster (1989), como la profesora Sandra Myers, subraya en su introducción, afirman estar asistiendo a una:

[...] ampliación de la definición de cultura que tendrá profundas implicaciones estéticas y políticas para el futuro. La cultura está llegando a ser vista más y más como la gama infinita de expresiones humanas que emerge tanto de nuestra singularidad como del terreno en que nos movemos [...] (p. 12).

Y continúa afirmando que esa definición dinámica responde a nuevos retos de gran relevancia en un mundo cuya demografía está cambiando.

En esta misma publicación, otra de las voces reconocidas en la economía cultural, el profesor J. Mark D. Schuster, realiza una crítica implícita al modo de realización de los estudios económicos sobre la cultura en los EE. UU. en aquel momento, citando las tres motivaciones principales tras los existentes (apoyo a las políticas, búsqueda de modelos y explicación de casos) y argumentando que, más que un análisis del valor, tenían objetivos políticos competitivos frente a las políticas europeas, más articuladas y generosas que las estadounidenses (pp. 16-17).

Steven C. Dubin (1987), en su detallado análisis del Acuerdo integral para el empleo y la formación (CETA) ${ }^{6}$ de los EE. UU. de 1973, aborda la complejidad de combinar los imperativos de la creación y el aparato burocrático para su control, a partir de la idea de que la cultura es, por su propia naturaleza, un proceso no racional o irracional, que casa mal con la voluntad de organizar a los artistas como fuerza de trabajo, pero que debe ser tratado más allá de la voluntad de ciertos intelectuales, como Susan Sontag, que abogan por acercarse al valor de la obra artística como una experiencia inaprehensible, que no puede ser analizada principalmente desde el punto de vista de las condiciones objetivas del proceso de trabajo creativo.

En el primer capítulo de su libro Pricing the Priceless (Valorando lo invaluable), William D. Grampp (1989) trata de reconciliar los conceptos de valor en la economía y en el arte y la cultura (the $\mathrm{Arts}^{7}$ ), cuando afirma que:

\footnotetext{
${ }^{5}$ Fernández León, J. (2018). ¿Para qué sirve la longitud del brazo? Una aproximación al origen de las políticas culturales en el mundo anglosajón. Periférica Internacional. Revista para el análisis de la cultura y el territorio (18). Recuperado de https://revistas.uca.es/index.php/periferica/article/view/4182.

${ }^{6}$ Ver https://definitions.uslegal.com/c/comprehensive-employment-and-training-act/

${ }^{7}$ Utilizaremos aquí indistintamente, para los textos en inglés, la traducción «arte» $\mathrm{O}$ «arte y cultura» para el término «Arts», que en la literatura de estudios culturales y de economía de la cultura se entiende de forma ambivalente.
} 
El sujeto (del libro) es el valor del arte: cómo es descrito por la economía y cómo lo describen las gentes de las artes de forma tan diferente cuando hablan de ello. Pero no cuando lo crean, coleccionan o exhiben, en cuyo caso actúan como economistas. La principal pregunta de este capítulo es en qué medida el valor que el mercado pone en las obras de arte es consistente con su valor estético. [...] Esta consistencia hace posible el cálculo económico (p. 15).

André Gortz (1989), un ingeniero químico devenido en pensador de la izquierda alternativa y vinculado ideológicamente al movimiento de pensamiento crítico de la Escuela de Frankfurt ${ }^{8}$, aborda el asunto del valor de la economía misma para comprender el mundo y trata de establecer los límites de lo que es económicamente pensable. Describe en las primeras páginas de su libro el propósito de «delimitar la esfera de lo que puede ser racionalizado» (p. 2), para señalar posteriormente la existencia de lo que denomina «Actividades autónomas» (pp. 164-169), establecidas a partir de la distinción clásica griega entre libertad y necesidad y la idea de que solo los individuos pueden ser libres cuando son liberados de la carga de las necesidades diarias, en términos de lo que Karl Marx denomina «los dos reinos», en la cual «la esfera de la felicidad comienza solo cuando acaba el trabajo determinado por la necesidad y las consideraciones mundanas». La libertad y la cultura «[...] comienzan más allá del reino de esa necesidad y se funden con el desarrollo de la energía humana que es un fin en sí mismo» ${ }^{9}$. Estas actividades, que son un fin en sí mismas, son:

[...] valiosas para y en sí mismas, no porque no tengan otro objetivo que la satisfacción y el placer que procuran sino porque la acción que logra el objetivo es tanto una fuente de satisfacción como el proceso de conseguir ese mismo objetivo: el fin se refleja en los medios y viceversa ${ }^{10}$ (Gortz, 1989, p.165).

El análisis de las lógicas enfrentadas de la producción, la difusión y el consumo de la cultura y la información en el capitalismo son los temas que Bernard Miège (1989) aborda en un trabajo con otra perspectiva menos optimista. Resume primero

\footnotetext{
${ }^{8}$ Son muchas las investigaciones publicadas sobre la Escuela de Frankfurt, un movimiento crítico surgido al abrigo de las vanguardias de la República de Weimar, en palabras de algunos críticos, un laboratorio del Movimiento Moderno. Sucesora heterodoxa de la Bauhaus, la primera gran escuela de arquitectura y diseño que definió el Movimiento, la Escuela, que nació como una iniciativa conjunta de la Escuela de arte municipal y la Städelschule, un instituto de arte nacido de una donación del magnate J. F. Städel, se erigió en el centro europeo del pensamiento crítico, especialmente por sus teorías en torno a la cultura y su visión crítica del papel de las industrias culturales en la conformación de la visión del mundo de la ciudadanía; contó entre sus filas con miembros y participantes tan destacados como Theodor W. Adorno, Walter Benjamin, Max Horkenheimer o Herbert Marcuse. Tras la llegada de Hitler al poder, la casi totalidad de sus miembros tuvo que huir de Alemania por sus ideas críticas frente al nazismo. En el libro de Jeffries, S. (2018) Gran Hotel Abismo. Una biografía coral de la escuela de Frankfurt, se ofrece un estudio detallado de este movimiento (Madrid: Taurus).

${ }^{9}$ Klagge, en un artículo publicado en 1986, Marx's Realms of «Freedom» and «Neccesity», refleja este conocido párrafo del capítulo 48 del tomo 3 de El capital de Marx.

${ }^{10}$ Veremos más adelante que esta idea de la cultura aparece tanto en la idea de la economía general antiutilitaria que propugnaba Georges Bataille en sus textos El límite de lo útil y La parte maldita, como en la actualización contemporánea de la teoría de lo sublime, en especial en la obra de J. F Lyotard.
} 
críticamente las percepciones de los economistas que denomina «neoclásicos» de la cultura (Baumol y Bowen, Blaug...) que han de explicar la contradicción entre la defensa del principio de que todo beneficio social óptimo es el resultado de las preferencias individuales, al tiempo que tratan de encontrar razones que justifiquen la presencia del Estado en la cultura, basada en la existencia de preferencias colectivas. Examina después otras visiones más críticas como las del Partido Comunista francés o las de autores del pensamiento crítico como Baran y Sweezy (1977) que analizan el valor de la cultura ya como unas necesidades en sí mismas, más allá de la oferta o como el resultado de las necesidades del capitalismo de crear demanda de mercancías culturales para consumir el superávit. En todas ellas encuentra dos problemas fundamentales no abordados: «1. El proceso de la formación de las necesidades culturales en un marco de relaciones económicas, políticas e ideológicas de clase. 2. El reconocimiento de la producción cultural como un aspecto específico de la valorización del capital» (p. 23).

Establece, entonces, su visión de que la producción cultural ya no puede ser considerada fuera de la esfera de la producción de mercancías, más allá de sus especificidades que, a pesar de que la creación cultural es a la vez productiva e improductiva y de que los productos culturales se presentan «en forma de un valor de uso, resultado del trabajo de uno o más artistas y se relaciona con los sentidos simbólicos asociados con ese uso. Pero son también mercancías producidas para ser intercambiadas» (p. 25).

Heilbrun y Gray (1993) abren su libro con una declaración rotunda:

En la era moderna la producción de arte ha ocupado una posición especial entre las actividades humanas. Algunos la calificarán como la más alta de las llamadas; muchos pensarán en ella como algo por encima del «mero comercio»; unos pocos desearían que los economistas quitaran sus sucias manos de ella (p. 3).

Pero arte y cultura son producidas por personas u organizaciones que habitan en el mundo real, y por tanto son sujetos de la economía general de cuyas limitaciones no pueden escapar por mucho que quieran; en su texto explican en detalle el funcionamiento del arte y la cultura en el marco de la economía general, señalando y reconociendo genéricamente las similitudes y también las diferencias de comportamiento entre los productores y consumidores de cultura y las personas y empresas que producen y consumen otros bienes y servicios. Sin embargo, de su investigación excluyen tanto las artes en vivo como el cine, la televisión y la industria editorial, ciñéndose a lo que ellos mismos viene a reconocer como «artes cultas», no abordando las citadas ni todas las formas de creación que agrupan bajo el epígrafe «cultura popular» (p. 5). Su punto de vista se mantiene, con cautelas, del lado de la economía clásica de la cultura, citando a Baumol y Bowen como maestros.

Con motivo de su incorporación a la primera cátedra mundial de Economía del Arte y la Cultura en la Erasmus University (Holanda), el profesor Arjo Klamer 
promovió un simposio en el que, desde distintos puntos de vista, se abordó el problema del valor de la cultura. En su aportación inicial a la publicación (Klamer, 1996), tras mostrar el escaso peso real de la economía de la cultura en el PIB del país y criticar los argumentos del mérito de la cultura, propios de la «aristocracia de las artes en su versión moderna», se propone mostrar a los economistas una versión distinta y verdadera de esa realidad. El arte, decía, no es solo una experiencia estética, no solo eso.

El arte también ocurre en la percepción de un problema, esto es, un problema de significación. En cada caso el arte existe no en la forma física de una pintura o una performance, sino en el momento de la maravilla, de la pregunta que ese hecho físico evoca en nuestra mente (p. 21).

El arte y los productos de la creación son pues ambiguos, ejercicios de admiración. Acercándose a la antropología y aceptando la crítica de quienes le califican como «romántico» avanza algunas ideas para configurar una teoría del valor no monetario ni medible del arte y la cultura. El arte, frente a las habituales operaciones monetarias, genera relaciones, procesos e intercambios; muchos de esos intercambios no son medibles y se basan en mecanismos de reciprocidad más que de cálculo. Las relaciones no pueden ser medidas por la teoría económica puesto que:

Una transacción comercial devalúa un bien cuyo valor está más allá de lo medible. Por eso cuando la fórmula del pago directo devalúa el bien comerciado, las partes tienen un incentivo para establecer maneras alternativas de financiar los costes de la producción del bien (p. 24).

Justifica los pagos indirectos a la cultura diferenciando el producto del arte del arte como actividad y como experiencia: afirma que el arte, tanto desde el punto de vista de la actividad como desde el de la experiencia «... tiene un valor más allá de cualquier medida y por tanto choca con la forma del dinero». La cultura es para él, el reino de los valores (un concepto cercano al del «reino de la libertad» de Marx, al que cita en su trabajo), un reino en el que la experiencia cultural no puede ser devaluada por la exigencia de medida de las transacciones comerciales.

Lo mismo se aplica a los valores científicos. Para sostener los valores del pensamiento crítico, el cuestionamiento, la argumentación abstracta y el compromiso intelectual, nosotros los científicos, tenemos que luchar contra la invasión de los valores comerciales y políticos [...] para sostener la conversación entre nosotros y mantener vivos esos valores.

Richard Caves (2000), para definir con claridad el campo de acción que analiza en su libro sobre los tipos de contrato a establecer entre el arte y el comercio, frente a la idea barajada por Grampp (1989) de que los artistas, al fin y al cabo, tenían las 
mismas opciones y tomaban las mismas decisiones que el resto de los mortales, sin especiales dones creativos, defiende que:

[...] los bienes y servicios de creación, los procesos de su producción y las preferencias o gustos de los artistas creativos difieren de forma sustancial y sistemática (si no universal) de sus homólogos en el resto de la economía, donde la creatividad juega un papel menor (y a veces, despreciable) (p. 2).

A partir de esta afirmación plantea cuales son, a su entender, las siete propiedades económicas de las actividades creativas: cuentan con una demanda incierta; sus trabajadores creadores cuidan su producto; tienen habilidades verticalmente diferenciadas; algunos de esos productos requieren la reunión de diversas competencias y habilidades para producirse; los productos mismos en su mayoría se diferencian mucho; el tiempo puede ser factor esencial para su existencia y consumo y muchos de ellos son duraderos y producen ingresos duraderos a sus creadores. Al mismo tiempo, tras afirmar que estos factores se dan por igual en los productos de alta y baja cultura, introduce en su preámbulo una definición de la alta cultura que es toda una declaración de percepción. Cita para apoyarla un conocido ensayo del crítico de arte neoyorkino Clement Greenberg (1961) en el que se afirma que, a diferencia de los productores de cultura popular, más dedicados a las satisfacciones inmediatas de los grandes públicos,

Los productores rigurosos de alta cultura se comprometen en un proceso innovador de experimentación y resolución de problemas en el que la forma trasciende y disuelve el contenido, mientras la respuesta directa y subjetiva del consumidor importa poco o nada en cuanto a su apreciación de la relación formal del producto creado con las fronteras estéticas del pasado.

Una diferencia de valor que el economista parece compartir pero que no diferencia en su valor y funcionamiento en el mercado a uno y otro tipo de productos culturales.

David Throsby, economista conocido de sobra en la especialidad y uno de los investigadores con más experiencia en el oficio, ha abordado desde sus primeros trabajos (Throsby y Withers, 1979) y a lo largo de su trayectoria y publicaciones un constante interés por introducir en el campo del pensamiento económico especializado el factor de los valores culturales como variante imprescindible para comprender la singularidad de los productos de la creación. Compartiendo con Bourdieu (1989) el término «capital cultural» (Throsby, 1999) trata de ir más allá de la concepción sociológica dominante en el uso del pensador francés y comienza delimitándolo como algo capaz de existir como un valor tangible o intangible, destacando que los factores históricos, sociales, de memoria colectiva, cualidad estética, significados simbólicos, determinan el principio de una definición problemática de ese capital. Afirma que, si esas características intangibles han de ser incorporadas al concepto, 
«con los formidables problemas de identificarlos y medirlos en la práctica» habrían de incluirse entonces «aquellas obras artísticas que existen en su forma pura como bienes públicos, tales como la música, la literatura y el conjunto de tradiciones, valores y creencias heredadas que constituyen la "cultura" de un grupo [...]». Aún más, añade que el capital cultural intangible puede encontrarse también en las redes y relaciones y manifestaciones culturales diversas en las distintas comunidades que sostienen la actividad humana, es decir, en los ecosistemas y en la rica diversidad cultural. En su primer gran trabajo de referencia (Throsby, 2001), para entender este camino de acercamiento entre los valores intangibles trataba ya, según él mismo señala, de fijar la diferencia entre el valor económico y el cultural, aun admitiendo que la teoría económica es central a la hora de explicar los sistemas de producción, la distribución y el consumo culturales «una comprensión integral de las relaciones entre los fenómenos culturales y económicos nos obliga a tener una visión más amplia». Nueve años después, abordará un trabajo más preciso para, en el marco de las políticas culturales, delimitar los elementos que definen los valores específicos de la cultura y la creatividad ${ }^{11}$ (Throsby, 2010). Comparando primero la creatividad artística y la científica, señala que, aunque no hay una definición simple de ambas, puede entenderse que:

[...] la creatividad artística incluye la capacidad e imaginación para generar ideas originales y nuevas formas de interpretar el mundo, expresadas en textos, sonidos e imágenes. Lo que puede compararse con la creatividad científica, que se relaciona con la experimentación y la resolución de problemas (p. 15).

Señala después las que considera tres características definitorias de los productos culturales: que hacen necesario algún tipo de aportación de la creatividad humana para su producción, que son el vehículo de mensajes simbólicos hacia sus consumidores y que contienen, al menos potencialmente, algún tipo de propiedad intelectual atribuible a la persona o colectivo que los produce. Se trata, pues, de bienes experienciales y sujetos a adicción racional, es decir, que si su consumo aumenta en el presente es previsible que siga aumentando en el futuro inmediato. A lo largo del texto, con referencias repetidas al hecho de que los valores culturales no pueden ser medidos únicamente en términos económicos, trata de identificarlos en torno a

${ }^{11}$ A lo largo del texto, se utilizan los términos «artes», «cultura» y «creatividad» como sinónimos del campo de lo cultural. Y, a partir de sus textos, puede entenderse que la visión del profesor Throsby comparte esencialmente esta categorización. Siendo conscientes de que, especialmente desde la aparición del término «industrias creativas» a fines del pasado siglo, términos como «creatividad», «ciudades creativas» y similares, han pasado a ser parte de argumentarios sociopolíticos contrapuestos, en el marco de las definiciones críticas de los mecanismos de producción del capitalismo contemporáneo. El profesor Oli Mould (2019) aborda informativamente este aspecto con detalle en Contra la creatividad. Capitalismo y domesticación del talento (Madrid: Alfabeto). Para una historia detallada de las industrias culturales y creativas, incluyendo las muy debatidas «ciudades creativas», puede consultarse el trabajo del profesor David Hedsmondhalgh (2012) The Cultural Industries. London: Sage. 
las preocupaciones espirituales, las consideraciones estéticas, o su contribución a la compresión de la identidad cultural por las comunidades. Intenta también determinar su diferencia con los valores creativos, que, señala, podrían ser la categoría superior, de productos esencialmente comerciales (publicidad, software, etc.) en la que los valores culturales podrían encuadrarse como una subcategoría diferenciada. Se trata de bienes que se incluyen en la categoría económica de bienes mixtos, es decir con valores públicos y privados al tiempo; y pueden identificarse tres fuentes de valores de la cultura externos al mercado: lo que define como «valor de existencia», es decir, el hecho de que las personas valoran algo solo por el hecho de que existe, el «valor de opción», es decir, la posibilidad de cualquier persona de elegir consumir cultura ahora o en cualquier otro momento en el futuro «y un valor de legado (la gente piensa que es importante transmitir la cultura a las generaciones futuras)» (p. 20).

Lo específico y diferencial de la cultura se acerca pues al campo de lo inconmensurable, casi se diría que Throsby comparte con el sociólogo Daniel Bell (1977) su amplia percepción del sentido y valor de la cultura ${ }^{12}$ :

El valor cultural [...] es un concepto multifacético que refleja cualidades tales como los valores estéticos, simbólicos, espirituales o históricos vinculados a un objeto específico. Desde luego, tales cualidades pueden afectar a valoraciones individuales del objeto en cuestión [...] Pero también hay un sentido en el que algunos de tales valores solo pueden percibirse plenamente en términos colectivos y no pueden ser representados sensiblemente en valoraciones monetarias individuales.

Referencia ineludible para comprender desde España los conceptos centrales de la economía cultural anglosajona es sin duda Ruth Towse. Profesora de Economía de las Industrias Creativas en la Universidad de Bournemouth, Emérita de la Universidad Erasmus de Rotterdam y responsable de algunas de las más influyentes compilaciones de textos sobre la economía de la cultura y sus perspectivas (Towse, 2005, 2010,2014 ) ha tenido una difusión especial en nuestro país, gracias al trabajo de sus traductores españoles, ambos economistas ${ }^{13}$. Defensora de la aplicación a la cultura de las herramientas de la microeconomía para su análisis, acoge con generosidad en sus manuales opiniones divergentes como la del ya mencionado Arjo Klamer, y las de otros expertos como Bruno Frey, al que más adelante haremos mención, pero su visión del valor de la cultura coincide bastante con la de los grandes economistas

12 Bell define así las modalidades de la cultura: «Las modalidades de la cultura son pocas y derivan de las situaciones existenciales que afrontan todos los seres humanos, en todos los tiempos, en la naturaleza de la conciencia: como se hace frente a la muerte, la naturaleza de la tragedia y el carácter del heroísmo, la definición de la lealtad y de la obligación, la redención del alma, el sentido del amor y del sacrificio, la comprensión de la piedad, la tensión entre la naturaleza animal y la humana, los reclamos del instinto y los frenos. Históricamente, pues, la cultura se ha fundido con la religión» (Bell, 1977, p.25).

13 Juan Prieto-Rodríguez y Víctor Fernández-Blanco mantienen una constante labor de investigación aplicada que aborda distintos campos de la economía de la cultura. https://www.unioviedo.es/juanprieto/ index_e.html y https://www.researchgate.net/profile/Victor_Blanco3. 
neoclásicos ${ }^{14}$, que siguen detentando el discurso central del análisis del valor centrado en los costes económicos. Erwin Dekker (2017) para demostrar esa posición, cita un párrafo de la introducción de su primer Manual de economía de la cultura (Towse, 2005) que reproducimos por su interés: «En su reciente Manual de economía de la cultura, Ruth Towse es un poco más sutil [que otros economistas], pero la desconfianza fundamental del argumento de los "bienes de mérito" se mantiene» (nótese las comillas para usar el concepto).

Citamos el párrafo más amplio, siguiendo la edición española, para una mejor comprensión de su posición:

[...] Todo ello deriva fácilmente en el dominio de la opinión de los expertos, a menudo financiados por el Estado frente a un consumidor-contribuyente incapaz de definir sus preferencias. Un argumento alternativo, aunque similar, que se utiliza como justificación para el hecho de reemplazar la decisión del mercado por la provisión colectiva es el concepto de «bien de mérito», empleado por los economistas para referirse a aquellos productos que, generalmente gracias a la opinión de los expertos, se considera tienen un valor intrínseco para la sociedad (Towse, 2004, p. 22).

El trabajo compilador de Towse, interesada en los progresos del análisis microeconómico, los estudios de impacto, las limitaciones de la economía del bienestar y especialmente las cuestiones de derechos de autoría, ha acogido voces discrepantes, pero siempre desde la altura amable de su posición. Véase si no este párrafo del manual: «Además, la profesión de economista acoge a unos cuantos disidentes, economistas que rechazan la ideología y hegemonía profesionales dominantes, especialmente el auge de la modelización matemática, escasamente relacionada con el mundo real» (p. 38).

\section{La cultura no da la felicidad (al menos de momento)}

Los trabajos de Bruno Frey, presentes inicialmente en español gracias a su divulgación por el Servicio de estudios económicos de la Caixa (Frey, 2000) de la mano del economista Pedro Schwarz, aplican el modelo de elección racional ${ }^{15}$ en numerosos estudios durante las últimas tres décadas, desde su primer texto relacionado con las artes (Frey y Pommerehne, 1989), a muchos otros relacionados con el valor de la cultura. Pero el aspecto de aquí se destaca es el relativo a

${ }^{14}$ Su trabajo de investigación, centrado en la economía de los derechos de autor, resulta muchas veces complementario del realizado por el que fue su marido, el economista Mark Blaug.

${ }_{15}$ Para una visión introductoria de la teoría de la elección racional y de algunas de las críticas a la misma, ver https://es.wikipedia.org/wiki/Teor\%C3\%ADa_de_la_elecci\%C3\%B3n_racional. Y especialmente la crítica de A. Sen (1977), Rational Fools: A Critique of the Behavioral Foundations of Economic Theory. Philosophy and Public Affairs, 6(4), 317-344. 
su trabajo en torno a la economía del bienestar y la felicidad (Frey, 2002, 2008, 2018). En estos trabajos, cita como antecedente principal más reciente las decisiones tomadas en 1972 por Jigme Singye Wangchuck, el cuarto Rey de Bután, que en su estrategia de cambio para su nación acuñó el concepto de Gross National Happiness-GNH (Felicidad Nacional Bruta) para sustituir al de Gross National Product (Producto Nacional Bruto) como principal fuerza motriz del país ${ }^{16}$.

Los estudios sobre la felicidad que el profesor Frey promociona son parte del debate filosófico y moral europeo desde Grecia, pero en estas últimas dos décadas han conseguido una notoriedad y reconocimiento internacional por Gobiernos como el Reino Unido, los EE. UU., Alemania, Japón o China e instituciones internacionales como la $\mathrm{OCDE}^{17}$, combinando esa vaga referencia a la filosofía oriental y una versión caritativa de la economía del bienestar, según entiende Wright (2013) «en una recuperación neoliberal tecnológicamente mejorada de la filosofía utilitaria de Jeremy Bentham».

Lo que destaca de Frey es el hecho de que un economista de la cultura, frente a buena parte del pensamiento humanista, acabe concluyendo que lo específicamente cultural, los saberes y las prácticas que «[...] -precisamente por su naturaleza gratuita y desinteresada, alejada de todo vínculo práctico y comercial- pueden ejercer un papel fundamental en el cultivo del espíritu y en el desarrollo civil y cultural de la humanidad» (Ordine, 2013, p. 9), no se encuentran en el centro de los indicadores de la felicidad. Afirma que:

De hecho, uno de los más importantes hallazgos ha sido el de que los aspectos no materiales de la vida de una persona -en particular las relaciones sociales entre los miembros de las familias, los amigos y vecinos- son importantes. La investigación sobre la felicidad se esfuerza en determinar cuantitativamente la importancia relativa de la personalidad genética y de los factores sociodemográficos, económicos, culturales y políticos (Frey, 2008, p. 4).

Considera también que los factores genéticos y de personalidad que determinan el bienestar colectivo, a pesar de estar en buena parte fuera del marco de la economía, son igualmente importantes puesto que la precisión de las estimaciones eco-

\footnotetext{
${ }^{16}$ En su tesis de fin de grado, G. Daga analiza en detalle los orígenes, contenido e impacto del GNH, y efectúa una crítica de sus limitaciones. El GNH incluye nueve áreas de evaluación, en una de las cuales se incluye la cultura, bajo el epígrafe de Diversidad y resiliencia Cultural, que se divide en cuatro subáreas: lenguaje nativo, participación cultural, habilidades artesanas y conducta. La evolución del proceso, conforme a este trabajo y a otras diversas fuentes, no ha conducido precisamente a una mejora de la vida cultural, sino a procesos de exclusión y persecución cultural de las minorías, convirtiéndose en un mecanismo de intolerancia cultural (42) que ignora los derechos de las comunidades, obliga a vestir los trajes tradicionales y a construir en el denominado estilo tradicional de Bután o persigue las lenguas minoritarias. (TY - THES AU - Daga, Gaurav PY - 2014/05/12 SP - T1 - Towards a New Development Paradigm: Critical Analysis of Gross National Happiness ER). https://www.researchgate.net/publication/262419781_Towards_a_New_Development_Paradigm_Critical_Analysis_of_Gross_National_Happiness

${ }_{17}$ Ver https://www.oecd.org/statistics/measuring-well-being-and-progress.htm
} 
nométricas de los efectos de los otros determinantes depende de forma relevante del papel de las diferencias de personalidad de las personas estudiadas. En cambio, en el caso español, el Observatorio Social de la Caixa parece haber decidido continuar con la línea inicial de Frey y publicaba el pasado año un estudio que bajo el título de El impacto de la cultura y el ocio en la felicidad de los españoles ${ }^{18}$ daba a la cultura un papel central en la generación de felicidad y bienestar personal.

\section{Las partes malditas, o la cultura no puede costar nada}

Frente al positivismo y la avalancha de datos cuantificables que sostienen los argumentos centrales de la economía de la cultura, como un análisis de una mercancía de valor mixto, otras muchas maneras de comprender la realidad social e histórica asignan a la cultura un valor diferente, incluso un papel central en el marco de una economía general diferente. Aunque bien es verdad que estas versiones son, en la literatura académica, el lado oscuro de la luna. Por eso, de forma genérica y en honor a uno de sus textos canónicos, se denominan aquí, genéricamente, las partes malditas. El breve tratado que Nuccio Ordine (2013) dedica a recoger las numerosas defensas de la cultura inútil, que, desde el tratado Sobre lo Sublime (Longino, 2014) han denunciado el daño que la economía del lucro inflige a la humanidad entera, incluye numerosas citas provenientes del mundo de las ideas, pero también de la economía. Una de ellas es de uno de los nombres imprescindibles en la historia de las políticas culturales del pasado siglo, John Maynard Keynes, promotor principal de las políticas culturales británicas y del Arts Council de su país tras la Primera Guerra Mundial. En el ensayo de 1930, Las posibilidades económicas de nuestros nietos, tras señalar la importancia que el buen uso del tiempo libre y de la cultura tendrían para la felicidad de las generaciones futuras, concluye con un párrafo terminante:

Pero, sobre todo, no nos permitamos exagerar la importancia del problema económico, o sacrificar a sus supuestas necesidades otros asuntos de mayor y más permanente significado. Debería ser un asunto para especialistas -como la odontología. Si los economistas lograran que pensáramos en ellos como gente humilde y competente, al mismo nivel que los dentistas, ¡eso sería espléndido! (Keynes, 1930).

Keynes era, no obstante, un utilitarista crítico y pensaba que la economía, con una mayor capacidad de generación de riqueza, sería capaz de alejarse del mercado, la producción y el consumo, y descubriría el valor de lo inútil. La realidad no le ha dado la razón. Otro pensador de su tiempo abordó el problema del valor de forma

${ }^{18}$ Ver https://observatoriosociallacaixa.org/es/-/el-impacto-de-la-cultura-y-el-ocio-en-la-felicidad-delos-espanoles. 
mucho más radical, poniendo en duda el principio mismo de la economía reinante: Georges Bataille ${ }^{19}$.

Bibliotecario de profesión, pero agitador cultural, políticamente comprometido ${ }^{20}$, Bataille ${ }^{21}$ sigue siendo permanente actualidad en los campos del pensamiento crítico como la filosofía del exceso y la exuberancia, los límites del sexo pornográfico y la contradicción permanente entre la orgía y la muerte como guías del placer y límites de la cultura humana. Recientemente, un número monográfico de la revista teórica Theory, Culture and Society (Melina Galleti y Roy Bayne, 2018) examina a través de diferentes artículos la relevancia y actualidad de su pensamiento y de su idea de la heterología ${ }^{22}$, el reto de todo aquello que las costumbres muchas veces califican como ilícito o incomprensible, para reclamar su espacio frente a los poderes constituidos que tratan de someterlas. Pero su presencia aquí tiene que ver con la conformación de la idea de valor, y de valor cultural para el cambio social, de dos de sus obras más ambiciosas, La parte maldita (1949) y su predecesora La noción del gasto (1932) en las que traza, a partir de la oposición entre lo racional y lo irracional una teoría de la economía general y del gasto basada en el exceso frente a las restricciones del capitalismo, como forma de respuesta transgresora a la conformidad social.

En su visión del devenir del mundo concibe una economía general, a partir de la idea de que la economía clásica parte de una falsa interpretación de la naturaleza de los movimientos económicos, en la que la energía, la del sol en primer lugar, es la categoría general de la que depende la economía y no una subcategoría de ésta. Somos y existimos desde la energía y no desde la economía. La energía del sol al llegar a la tierra se expande alimentando a todo lo vivo, que la explota para transformarla en energía de supervivencia, en vida. Pero todos los seres vivos (su ejemplo son las plantas) producen un exceso de energía que solo en parte se reutiliza. Una parte se derrama, se pierde o ha de ser gastado en valores como la belleza de sus hojas o, simplemente se malgasta.

Bataille está influido sin duda por la lectura del Ensayo sobre el Don de Marcel Mauss $(2009)^{23}$, que aborda los procesos de intercambio en las sociedades primitivas

\footnotetext{
${ }^{19}$ La dimensión de este capítulo del texto no puede hacer justicia, siquiera de forma resumida, a la importancia de las publicaciones de Bataille y a su teoría de la economía general y del gasto improductivo, del que la cultura y la creación forman parte fundamental. Por eso, además de la recomendación de la lectura de los textos del autor, se incluyen en la bibliografía general algunos textos que examinan el asunto en detalle (Richardson, 1994; Botting, 1998; Plotnisky, 1993...)

$20 \ll(. .$.$) De esta forma el movimiento obrero y la política de izquierdas, como mínimo liberal, con res-$ pecto a los asalariados, significan principalmente, al oponerse al capitalismo, que una parte de riqueza más grande es dedicada al gasto improductivo» (Bataille, 1967, 83).

${ }^{21}$ Para un resumen biográfico, ver https://www.popsubculture.com/pop/bio_project/georges_bataille. html

${ }^{22}$ La heterología es la senda en la que se encuentran las ideas de pensadores contemporáneos, en cierta forma deudores de Bataille, como J. F. Lyotard, al que se cita más adelante por su actualización de la teoría de lo Sublime, o J. Baudrillard. Un texto que aborda este ámbito es Pefanis, J. (1991). Heterology and the Postmodern: Bataille, Baudrillard and Lyotard. Durham NC: Duke.

${ }^{23}$ Su amigo y colaborador, Jean Piel, en la introducción a La parte maldita, señala la importancia de este descubrimiento para Bataille, como uno de los orígenes de su interés por los fenómenos económicos que abordará tanto en La noción del gasto como en esta obra, escrita diecisiete años más tarde.
} 
y ve en su origen no un proceso de gasto en el que el proceso de adquisición es claramente secundario frente al valor de la pérdida suntuaria, principio regulador de esos intercambios. Establece primero una crítica del principio clásico de utilidad, que no es capaz de contener los valores reales de la vida humana, y para el que:

El placer, tanto si se trata de arte, de vicio tolerado o de juego, queda reducido, en definitiva, en las interpretaciones intelectuales corrientes, a una concesión, es decir, a un descanso cuyo papel sería subsidiario. La parte más importante de la vida se considera constituida por la condición -a veces incluso penosa- de la actividad social productiva (Bataille, 1987, p. 26).

Porque en una sociedad utilitaria el ser humano es incapaz de justificar utilitariamente su conducta, no cayendo en la cuenta de que «una sociedad humana puede estar interesada, como él mismo, en pérdidas considerables [...] que provoquen, según necesidades concretas, abatimientos profundos, ataques de angustia y, en último extremo, un cierto estado orgiástico».

En su examen del principio de pérdida, señala como la actividad humana no puede reducirse a esos procesos de producción, conservación y consumo capitalistas, que componen el mínimo vital necesario, sino que su identidad fundamental está basada en los llamados gastos improductivos: «el lujo, los duelos, las guerras, la construcción de monumentos suntuarios, los juegos, los espectáculos, las artes...» un conjunto de gastos incondicionales, contrarios al principio económico de la contabilidad, que constituyen lo esencial de la economía de la vida. Así cita el valor simbólico de los objetos para cuya posesión se sacrifican fortunas, el sacrificio y la producción de formas sagradas el gasto de dinero y energías de los espectáculos deportivos, incluyendo el placer adicional de los peligros inherentes a ciertas prácticas, y, de forma detallada, los gastos culturales. En ellos, reconociendo la existencia de gastos reales en algunas de sus formas (la arquitectura, la música, la danza) afirma la primacía absoluta en su valor de su carácter de gasto simbólico. Por eso afirma que, en cierta medida «la función creativa compromete la vida misma del que la asume, puesto que lo expone a las actividades más decepcionantes, a la miseria, a la desesperanza, a la persecución de sombras fantasmales [...] o a la rabia» (p. 30). Concluyendo su tesis, afirma la necesidad de contar con una economía que acepte que no vale nada, el excedente improductivo del que forma parte la cultura, como el centro de una convivencia superadora de las desigualdades sociales. La vida humana, más allá de su obligación ante la ley no puede quedar limitada a los sistemas que se le asignan en las concepciones racionales tradicionales, sino todo lo contrario. Así, escribe:

[...] el inmenso trabajo de abandono, de desbordamiento y de tempestad que la constituye podría ser expresado diciendo que la vida humana no comienza más que con la quiebra de tales sistemas. Al menos lo que ella admite de orden y de ponderación no tiene sentido más que a partir del momento en que 
las fuerzas ordenadas y ponderadas se liberan y se pierden en fines que no pueden estar sujetos a nada sobre lo que sea posible hacer cálculos. Solo por una insubordinación semejante, incluso aunque sea miserable, puede la especie humana dejar de estar aislada en el esplendor incondicional de las cosas materiales (p. 42).

He ahí un somero resumen de otro sentido y valor de la cultura. Una cultura liberada de las ataduras de la racionalidad productivista y liberada de los corsés del funcionalismo que la reclama para formar parte de un sistema que se agota en su pobre eficacia contable.

\section{De lo sublime a la inmanencia}

Tiene también relevancia, en el panorama del pensamiento sobre el valor de la cultura, la categoría de lo sublime a la que antes hacíamos mención, presente en un gran número de autores que, desde la filosofía a la estética, examinan los procesos de la creación artística. Desde el ya citado texto de Longino a la filosofía de Kant o las ideas de Burke ${ }^{24}$ son numerosas las perspectivas en torno a aquello que Kant (1999, p. 199) considera un sentimiento contradictorio, en el que dolor y placer se mezclan necesariamente. «[...] Un sentimiento de dolor que nace de la inadecuación de la imaginación, en la apreciación estética de las magnitudes, con la apreciación mediante la razón [...]» al tiempo que un placer que nace de concordancia de ese juicio con las ideas de la razón. Es Jean François Lyotard, quizá el pensador contemporáneo que mejor expresa ese conflicto en el que se mueve esta apreciación. Y lo hace en un artículo de referencia, publicado en 1984 en la revista Artforum $^{25}$, a propósito del trabajo del pintor Barnett Newman.

Su argumento, aludiendo a un ensayo publicado en 1948 por Newman, titulado Lo Sublime es ahora, comienza así:

¿Cómo debe uno entender lo sublime -pensemos en ello como el foco de una experiencia sublime- como un «aquí y ahora»? $\mathrm{O}$ al contrario, ¿no es esencial a esta sensación aludir a algo que no puede ser demostrado o, como Kant dijo, Presentado?

A lo largo del ensayo, recorriendo la historia del término y a los pensadores citados añade a Boileau, el traductor del libro de Longino, que, en el prefacio para presentar la obra afirmaba que «lo sublime no puede ser enseñado y la didáctica no tiene capacidad alguna al respecto»; lo sublime, asegura Boileau, no se atiene a reglas que

\footnotetext{
${ }^{24}$ Ver Burke, E. (1997). Indagación filosófica sobre el origen de nuestras ideas acerca de lo sublime y lo bello. Madrid: Tecnos.

25 Aunque existen diversas versiones del texto, entre ellas una versión en castellano (Lyotard, 1992), Peregrinaciones. Madrid: Cátedra). Hemos usado para las citas el texto original de la revista.
} 
puedan determinarse a través de poéticas; lo sublime solo requiere que hablantes u oyentes cuenten con el necesario gusto y rango conceptual, la habilidad para sentir «lo que el mundo siente primero».

Lyotard continúa su análisis reinterpretando las ideas de Burke, Kant y Boileau desde una perspectiva que denomina freudiano-lacaniana, para concluir que, tras ellas, de uno u otro modo, se define un campo de posibilidades para la expresión artística que las vanguardias históricas consolidarían (aunque seguramente ninguno de sus miembros hubiera leído ni a Kant ni a Burke). Esa herramienta de la indeterminación, presente en lo que no puede ser normado ni descrito del todo, es la que permite a los artistas comenzar a intentar combinaciones para crear eventos, situaciones muchas veces chocantes. Dice Lyotard:

El amateur no experimentará ya más simple placer ni derivará del contacto con el arte algún beneficio ético, sino que en su lugar podrá esperar una intensificación de su capacidad conceptual y emocional, una felicidad ambivalente. [...] La comunidad social no se reconocerá ya más en los objetos artísticos, sino que los desdeñará, los despreciará por incomprensibles y entonces podrá aceptar que la vanguardia intelectual se ocupe de preservarlos en museos como restos del delito que den testimonio del poder y la pureza del espíritu.

La llegada de la estética de lo sublime al arte de los siglos XIX y XX se convierte pues en el testigo de esa indeterminación que marca y define la cultura. Pero en ese proceso, con el advenimiento de la sociedad del espectáculo y de la especulación del mercado artístico, se rompe el principio de validez de lo impresentable ${ }^{26}$ para ser sustituido por el de una creación que, a través de esas presiones de lo espectacular y guiada por intermediarios culturales, ha de comportarse como cualquier novedad de mercado puesto que es necesario que su complejidad inalcanzable no desanime a los compradores.

En medio del mercado omnipresente, es difícil hoy encontrar esa categoría, cercana en cierto modo al aura definida por Walter Benjamin ${ }^{27}$, que Byun Chul Han (2017) ve destruida por la sociedad de transparencia digital, aunque rasgos de esa otredad que se evapora en el aire, parte del cuerpo de esos valores intangibles -e inconmensurables- de la cultura, siguen apareciendo en el pensamiento contemporáneo.

El filósofo y sociólogo de la cultura Néstor García Canclini (2010) nos lo recuerda, citando a José Luis Brea ${ }^{28}$ y a Juan Antonio Ramírez ${ }^{29}$ para explicar su persistencia. Y adelanta su propia percepción del valor, la idea de inminencia, el resultado

${ }^{26}$ Una excelente aproximación a la visión de lo impresentable y lo sublime en Lyotard puede encontrarse en Santamaría, A. (2017). La problemática de lo impresentable: La lectura de Jean François Lyotard del expresionismo abstracto americano. En Aisthesis, n. ${ }^{\circ} 62$.

${ }^{27}$ Walter Benjamin (2013), uno de los grandes pensadores independientes próximos a la Escuela de Frankfurt, afirma que «El rastro es la manifestación de una cercanía, por lejos que pueda estar de aquello que lo deja. el aura es la manifestación de una lejanía, por muy cerca que pueda estar aquello que la irradia»

28 Brea, J. (1991). Las auras frías. El culto a la obra de arte en la era postaurática. Barcelona: Anagrama.

29 Ramírez, J. (2009). El objeto y el aura. (Des)orden visual del arte moderno. Madrid: Akal. 
de quienes crean «haciendo algo que no saben bien qué es». Comparte con Lyotard la idea del presente agónico, y hace hincapié en que, a su entender, el mercado ha postrado a la creación que no quiere ser únicamente cosificada como mercancía, y lo denuncia dramáticamente: afirma de manera rotunda que asistimos a un proceso de reestructuración, o de descomposición radical de lo público, que se muestra a través de un extendido malestar y un creciente desorden social. «Las reacciones oscilan entre las propuestas críticas y las insurrecciones locales, la recepción escéptica de las promesas hegemónicas y la búsqueda de vías distintas, fuera de la organización legal, para satisfacer necesidades y encontrar sentido» (p. 187) y, centrando su análisis en el mercado del arte, «...dominado por galerías líderes con alto poder económico, museos, bienales y ferias» (p. 189). García Canclini confía aún en el poder de la creación, del arte: «Quizá su especificidad reside en ese modo de decir que no llega a pronunciarse plenamente, en esa inminencia de una revelación» (p. 60). Para afrontar esta crisis del valor de la cultura, considera necesario «detenerse en lo cualitativo, en la densidad intranquilizante de los hechos» (p. 250), describiendo una estética de la inminencia en la que:

[...] el arte no es autónomo, sabe que la posibilidad de abrirse a lo nuevo, captarlo o dejarlo huir, está ligada a prácticas que, lejos de realizarse en el vacío, operan en medio de condiciones desiguales bajo límites que los artistas comparten con quienes no lo son (p. 251).

La tarea del arte, concluye, no es la de dar un relato a la sociedad que organice su diversidad, sino valorizar lo inminente donde el disenso es posible.

\section{Otras miradas al valor: de lo excelso al conflicto}

Peter Sloterdijk (2002) y Boris Groys $(2005,2008)$ son dos filósofos y compañeros de Facultad en Karlsruhe, que mantienen un activo pensamiento crítico en torno al arte, la creación, la religión y la ciudadanía. El primero, en su ensayo El desprecio de las masas. Ensayo sobre las luchas culturales de la sociedad moderna, tras un análisis de la aparición de la masa moderna en la sociedad de la información y su crecimiento en la sociedad digital, concibe la cultura como un reactivo contra la banalidad del universo unidimensional en el que se mueve el consumo cultural, señalando como «la cultura, en el sentido normativo que hoy más que nunca se hace necesario evocar, constituye el conjunto de tentativas encaminadas a provocar a la masa que está dentro de nosotros y a tomar partido contra ella». Y considera que el esfuerzo del trabajo cultural valioso hoy promueve y resalta nuestra capacidad de admiración, «[...] se orienta a no perder por completo la altura de lo excelso», representando lo opuesto a «esa crítica que, ubicada de un modo totalitario en un punto central, no elogia más que lo que allí encuentra». Boris Groys propone en Sobre lo nuevo. Ensayo de una economía cultural (2005), una idea del valor de la cultura en la que: 
A la obra de arte o a la obra teórica ya no se la interpela y se la enjuicia por su conformidad a la tradición cultural sino por su relación con la realidad exterior de la cultura. De aquí deriva una ambigüedad que a lo largo de la historia ha puesto crecientemente en cuestión el concepto de verdad. Pues para que un producto cultural pueda significar, describir y manifestar la realidad exterior a la cultura, ese producto debe, en primer lugar, distinguirse de esa realidad. Esa distancia a la realidad que indica su pertenencia a la cultura es la condición necesaria de su semejanza a la realidad que está fuera de la cultura (p. 23).

Más adelante en el libro presenta las bases de una «economía cultural del intercambio», que define como:

[...] el trueque, o el cambio, o el canje que tiene lugar entre el espacio profano y la memoria culturalmente valorizada, que consiste en la suma de los valores culturales que se conservan en los museos, las bibliotecas y en el resto de los archivos, así como en las peculiaridades, rituales y tradiciones de la relación con esos archivos.

Para él los procesos de innovación son los generadores de los cambios que determinan que algunos materiales del espacio profano adquieran valor y se incorporen a los archivos-memoria de la cultura y, al tiempo, otros valores culturales pierden valor y son devueltos a ese mismo espacio profano. Y nos incita en su Bajo sospecha (2008) a una muy sugerente lectura del pensamiento económico sobre la cultura en la obra de Mauss, Claude Levi-Strauss, Bataille, Lyotard y Jacques Derrida.

Entre la gran tradición de investigación en el campo de los estudios culturales del Reino Unido, Terry Eagleton (2001, 2017), discípulo de Raymond Williams, ocupa un lugar singular, por su visión crítica de los mecanismos de análisis y su lectura independiente de proceso de definición del valor de la cultura. Señala que «La cultura... hereda el majestuoso manto de la autoridad religiosa, pero también sus incómodas afinidades como la ocupación y la invasión. Entre esos dos polos, uno positivo y otro negativo, queda localizado el concepto de cultura...» (Eagleton, 2001, p.12). Reflejando levemente la célebre cita de Benjamin. «No hay documento de cultura que no sea al tiempo de barbarie» (Benjamin, 2008, p. 309), subraya la ambivalencia del término mismo, avanza, a partir de la idea de Williams (2008) de que, desde comienzos del pasado siglo la cultura ya no es principalmente una crítica de la manufactura moderna sino un sector muy rentable de esta aunque la cultura de las vanguardias y sus sucesores, confiados en su autosuficiencia, «daba la espalda a la existencia cotidiana, oscureciendo su lenguaje, trastocando sus significados, entremezclando sus narraciones y fragmentando sus formas a fin de evitar ser consumía con demasiada facilidad» (Eagleton, 2017, p. 159). Crítico con la transformación del valor crítico del arte en una fusión con las industrias culturales que inhabilita su función, y reclamando la construcción de un nuevo lenguaje del valor de la cultura capaz de fundir popular y culto. La cultura, resume, «[...] ha perdido su inocencia... 
atrapada en una variedad peligrosamente inflamada de nacionalismo, ligada a una antropología racista, absorbida en la producción general de mercancías e inmersa en los conflictos políticos». Su desesperanza le anima a proponer que si se quieren salvar los valores sanadores, sociales y de cambio de la cultura, las políticas culturales debe dar un paso atrás, tras haber perdido su función y jerarquía, deben afrontar el debate en torno al concepto de valor en nuestras sociedades contemporáneas desde una perspectiva de política subalterna, subsumida en las respuestas a los retos actuales, el hambre, las guerras, las armas, las migraciones, los desastres ecológicos... que conforman la agenda mundial del futuro.

Eleonora Belfiore es una de las más activas investigadoras internacionales en torno al valor de la cultura y la democracia cultural. Y explora la relación entre la cultura y la política, como condición para la determinación real del catálogo de valores a través de la acción de los gobiernos. Sus numerosos trabajos al respecto, incluyendo la coordinación del más importante informe sobre el tema en los últimos años, el Informe Warwick $^{30}$ sobre el futuro del valor de la cultura (2015), la ha llevado a profundizar en el debate sobre ese valor y a poner el acento crítico en su ubicación. En un reciente artículo de 2018, a propósito de sus últimas experiencias de investigación de prácticas culturales de comunidades excluidas, señala como los procesos de ubicación del valor cultural se han convertido en un espacio nada neutral de debate intenso en Gran Bretaña, debate ensombrecido a partir de la llegada, a fines del siglo pasado, del discurso de las industrias culturales ${ }^{31} \mathrm{y}$ su preminencia en la investigación y la economía de la cultura. Un debate en el que hay ganadores y perdedores y en el que los discursos de política cultural solo parecen poner el acento en los primeros. Porque son esas ideas sobre el valor de la cultura las que conducen el establecimiento de prioridades políticas y ubicación de recursos públicos para la cultura. Y es necesario, según su criterio, analizar las mismas en términos de interés público, exigir transparencia y procedimientos democráticos en los procedimientos y comprobar en qué medida es responsabilidad pública la atención de los sectores perdedores en el combate hegemónico, asuntos sobre los que ha publicado trabajos de referencia (Belfiore, 2012 y 2015).

\section{El valor de la cultura como derecho universal}

La consideración de la cultura como un derecho universal y los derechos culturales de la ciudadanía comienzan a ser materia de estudio académico, pero son aún pocas las obras que abordan en perspectiva este aspecto del valor de la cultura. En su reciente edición de un libro recopilatorio al respecto, Andrzej Jakubowski (2016)

\footnotetext{
${ }^{30} \mathrm{https}$ //warwick.ac.uk/research/warwickcommission/futureculture/finalreport/warwick_commission_ final_report.pdf

${ }^{31}$ Fernández León, J. (2018). Democracia cultural y promesas de dinero. Políticas culturales y arm's length en la esfera anglosajona, hoy (II). Periférica Internacional. Revista para el Análisis de la Cultura y el Territorio, 19, 54-69. Recuperado de https://revistas.uca.es/index.php/periferica/article/view/4903.pdf
} 
aborda el marco definitorio de dichos valores: desde el punto de vista de los derechos colectivos, subraya, los derechos culturales no tienen como objetivo la preservación del patrimonio cultural, sea este tangible o intangible.

Los derechos culturales implican el asegurar las condiciones necesarias para facilitar a todos, sin discriminación y en una base igualitaria, el contribuir a la vida cultural en constante evolución de tantas -o tan pocas- comunidades de las que elijan formar parte. Los elementos centrales de los derechos culturales se relacionan con el derecho de cada persona a acceder, participar en y contribuir a la vida cultural en toda su diversidad [...].

Y están íntimamente ligados a otros derechos como la libertad de información y comunicación, de creencias y expresión, uso de la lengua y educación.

La historia de los derechos culturales nos remite inevitablemente, por consiguiente, a un marco normativo internacional. En su trabajo en torno al derecho universal de acceso a la cultura, Belén Barreiro (2013), revisa en detalle algunas de las publicaciones de referencia al respecto y resume el conjunto de las disposiciones internacionales más relevantes, citando la importancia de la adopción, por parte de la Asamblea General de las Naciones Unidas en 2008, del Protocolo Facultativo del Pacto Internacional de Derechos Económicos, Sociales y Culturales ${ }^{32}$, continuador del Pacto Internacional de Derechos Económicos, Sociales y Culturales de $1996^{33}$. Este protocolo, firmado y ratificado por España en 2010, ha sido reconocido ya por 49 países de los cinco continentes (bien es cierto que ninguna de las grandes superpotencias, excepto Francia e Italia, la han ratificado todavía) y aspira a generar un marco general de derechos culturales sostenibles. Pero esa ratificación universal comenzó antes, en el marco de las constituciones nacionales nacidas de la eclosión de los Estados nación.

El filósofo y profesor de Filosofía lógica y Método científico de la London School of Economics, Ernst A. Gellner, publicaba en 1983 una de las obras más influyentes a la hora de rastrear el origen cultural del Estado nación: Nations and Nationalism. En sus páginas abordaba las bases históricas de la constitución de los Estados contemporáneos. Y lo que daba legitimidad a los mismos, la base esencial del Estado moderno, afirma, no era ya solamente la detentación de la violencia legítima, sino el cuasimonopolio de la cultura:

Hoy en día, las culturas parecen ser las depositarías naturales de la legitimidad política. Solo entonces constituye un escándalo cualquier desafío que hagan unidades políticas a sus fronteras. Es en estas condiciones, y solo en ellas, cuando puede definirse a las naciones atendiendo a la voluntad y la cultura, y, en realidad, a la convergencia de ambas con unidades políticas. En estas

\footnotetext{
${ }^{32}$ https://www.ohchr.org/SP/ProfessionalInterest/Pages/OPCESCR.aspx

${ }^{33} \mathrm{https}$ ///www.ohchr.org/SP/ProfessionalInterest/Pages/CESCR.aspx
} 
condiciones el hombre quiere estar políticamente unido a aquellos, y solo a aquellos, que comparten su cultura. Es entonces cuando los Estados quieren llevar sus fronteras hasta los límites que define su cultura y protegerla e imponerla gracias a las fronteras marcadas por su poder (p. 80).

La cultura, especialmente la lengua dominante y homogeneizadora (y como analiza Gellner en esta obra, una determinada homogeneización cultural que delimita y contrae la pluralidad, llegando muchas veces a exterminarla) se constituye pues en uno de los principios básicos de las constituciones que irán naciendo en Europa en el siglo XIX. Llega Gellner en este trabajo a una sugerente conclusión:

Así pues, la economía, tanto como el estado central, necesita también el nuevo tipo de cultura central; la cultura necesita el estado; y el estado probablemente necesita que su manada lleve un hierro cultural homogéneo en una situación en la que no puede apoyarse en subgrupos considerablemente desgastados [...]. Es la cultura, y no la comunidad, quien marca las normas internas tal y como son. En pocas palabras, la relación entre estado y una cultura moderna es algo bastante nuevo y surge irremediablemente de las exigencias de una economía moderna (p. 178).

Esta relación entre Estado, Economía y regulación homogeneizadora da a la cultura un papel central en la vida de las comunidades nacionales. La cultura se constituye así en un derecho de las mayorías.

La brillantez argumental de Gellner no oculta el problema de ese principio, contrario al de la pluralidad garante de los derechos de las minorías y de sus valores culturales propios. Así lo recoge el profesor Prieto de Pedro (1996) en su obra exhaustiva sobre los derechos culturales y la normativa jurídica que los ampara, en la que de forma detallada examina el devenir de la historia de la constitución jurídica de la cultura como un bien universal, trazando los conflictos generados por esa visión hegemónica y excluyente que inicialmente sumaba como derechos únicamente los valores culturales de la mayoría nacional. El corazón del trabajo, el detallado análisis de la Constitución española (con la mención a otras recientes como la portuguesa o varias en América Latina), incide en la singularidad de esta, que fija en su texto como las antecitadas, la idea del «derecho a la cultura», diferenciada de la más genérica de «derechos culturales», presente en diversas constituciones europeas. Por ello, asegura:

La Constitución española, así como la portuguesa, al positivar en sus textos la cultura como «derecho», han dado un paso decisivo en pro de su consolidación, en estricta técnica jurídica, como un derecho fundamental autónomo, en concreto como un derecho de prestación. [...] que implica una previa acción positiva del Estado, a fin de que los individuos puedan ejercerlo (p. 280). 
Pero no solo del campo de la filosofía y el derecho podemos extraer valoraciones de la cultura como un derecho universal. El profesor David Throsby, mencionado en páginas anteriores, es bien conocido por su permanente preocupación para sumar al sentido utilitario del campo profesional los valores propios y específicos del ámbito cultural. Como señala en las conclusiones de su texto sobre políticas culturales y economía, tras mostrar su creciente preocupación por la forma en que diversos estudios aplicados a las políticas culturales han manipulado o ignorado los efectos del tecnocapitalismo,

[...] y la tendencia dominante del paradigma neoliberal a la hora de guiar las políticas de los países, trasladando el centro del poder de los Gobiernos al sector privado y disminuyendo así el papel del sector público a la hora de priorizar asuntos como la igualdad o el respeto a los derechos humanos (Throsby, 2010, p.233).

Citando a McGuigan (2004) afirma que un área de los estudios de políticas culturales, profundamente concernida con las formas en que se abordan temas profundos de justicia social y cultural es aquella que los conecta con una agenda internacional de desarrollo de políticas culturales. Esta área de compromiso político nace, a su entender, de tres motivos: una apreciación de los valores vinculados a la diversidad cultural y a la creciente importancia de esa diversidad en la vida económica social y cultural, el reconocimiento de la importancia del diálogo intercultural como medio para la reducción de las tensiones y conflictos culturales (y en busca de un mayor sentido de comprensión y respeto mutuo entre países) y la afirmación del papel fundamental de los derechos humanos como pilar de la política cultural.

\section{A modo de estado de la cuestión. ¿Qué vale la cultura para los países? El valor de la cultura en Europa y Estados Unidos hoy}

El valor económico de la cultura es pues, como reconocen los propios economistas del sector, tan solo un elemento de los que componen el valor agregado de la misma. Y se ha tratado en las páginas anteriores de presentar un somero panorama de la diversidad de percepciones existentes a la hora de establecer mecanismos de medida y reconocimiento de ese valor, teniendo en cuenta su complejidad y el número de factores cuantitativos y, sobre todo, cualitativos que incorpora. Los que hoy siguen siendo hegemónicos son aquellos que consideran que la cultura es principalmente una mercancía, igual o similar al resto de las que componen el mercado. Un buen termómetro de medida de la preocupación de los países por la cultura es la actitud de la política hacia ella y su reflejo en los presupuestos

Los días 16 y 17 de junio pasados, convocados por la Dirección General de Cooperación y Desarrollo (DEVCO) en Bruselas, 400 expertos y profesionales elaboraron un documento en torno al valor de la cultura y la creatividad y su contribución al 
desarrollo sostenible. Bajo el título de Manifiesto Cultura para el futuro ${ }^{34}$ establece un campo de valores para la cultura que abre una puerta al desarrollo de trabajos de investigación cualitativa con nuevas prioridades: Derecho humano fundamental, respeto a la diversidad y diálogo intercultural, igualdad de género, desarrollo sostenible, promoción de cambios de comportamiento, pertenencia compartida, reducción de desigualdades, laboratorio de innovación social... un conjunto de descriptores que sugieren la conveniencia de nuevas miradas en torno al valor de los productos culturales. En su introducción señala que:

La cultura posee valor intrínseco y es propulsora de cambio e innovación social. La cultura está reconocida como un pilar del desarrollo sostenible. En calidad de agente facilitador, la cultura es un potente vehículo para la comunicación y la promoción de cambios en el comportamiento. Por ello, debería contribuir en gran medida a los progresos para alcanzar las metas y Objetivos de Desarrollo Sostenible.

La cultura, señala el texto, es un derecho humano fundamental, puesto que desde ella, se promueve la libertad de expresión, la diversidad cultural y la igualdad de género. Defiende también la capacidad del sector cultural para reducir las desigualdades y la creación de puentes entre comunidades a través de la cooperación y el diálogo intercultural, cimentando confianzas y fomentando un sentimiento compartido de pertenencia. Esta declaración considera pues que la cultura es un elemento crucial, en un mundo plagado de ataques contra los derechos humanos, la libertad y la democracia, además de una plataforma para abordar desafíos sociales centrales «...gracias a su capacidad de provocar intensas respuestas cognitivas y emocionales». Propone a continuación experimentar, fortalecer la visión y la confianza, y desarrollar un repertorio de prácticas a través de programas educativos. La cultura ha demostrado ser una herramienta efectiva en el fomento de la prevención y la resolución de conflictos, creando espacios para la libre expresión, el intercambio, la comprensión mutua y la consiguiente cohesión social. De ese modo la cultura y sus escenarios se convierten en un verdadero laboratorio de innovación social.

La mención al valor económico de la cultura, factor esencial en las políticas de la Unión Europea en sus documentos y declaraciones recientes sobre políticas cultura$\operatorname{les}^{35}$, queda relegada, en el preámbulo del Manifiesto, a un párrafo breve, que poco tiene que ver con las prioridades hasta ahora establecidas por la Comisión Europea en la materia. Dice así:

Más allá de su papel en la búsqueda del desarrollo humano sostenible, la cultura es cada vez en mayor medida un motor de crecimiento económico. La

\footnotetext{
${ }^{34}$ Ver https://culture4future.eu/wp-content/uploads/2019/08/CoC-ManifestoES-20190810.pdf

35 Ver https://eur-lex.europa.eu/legal-content/ES/TXT/HTML/?uri=LEGISSUM:1002_4\&from=ES https://eur-lex.europa.eu/legal-content/ES/TXT/HTML/?uri=LEGISSUM:1002_1\&from=ES
} 
protección, conservación y valorización del patrimonio cultural y de las industrias culturales y creativas estimulan el empleo, empoderan a la juventud y a las mujeres y contribuyen a la creación de comunidades sólidas y tolerantes, respetuosas con las diferencias culturales.

Se trata tan solo de un documento interno, pero de su redacción puede quedar al menos la esperanza de que el tratamiento de la cultura en la UE recupere un poco ese carácter de derecho que hasta ahora la práctica de la Comisión Europea venía relegando, frente a las preocupaciones por reforzar el capítulo presupuestario de la Europa Creativa. Tiempo habrá de comprobarlo.

Mientras tanto, la situación de la financiación en los países anglosajones, tradicionalmente favorables a valorar la cultura como un hecho privado y, por tanto, gestionado desde las preferencias individuales y el patrocinio personal y corporativo, continúa preñada de amenazas para los fondos públicos dedicados a la cultura. En Gran Bretaña los fondos para la cultura se siguen reduciendo cada año desde hace casi una década ${ }^{36}$. Y en Estados Unidos están en peligro de cierre aquellos como los destinados al National Endowment for The Arts (NEA) y al National Endowment for Humanities (NEH), que dedican los escasísimos fondos de sus presupuestos (155 millones de dólares cada una, este año 2019) a fomentar los valores de la pluralidad, el experimento y el riesgo creadores. Cada año el presupuesto presentado por el actual Presidente ${ }^{37}$ retira la totalidad de sus fondos a ambas instituciones, a las que tiene amenazadas de desaparición desde su llegada. Y aunque el Congreso de los EEUU siga, finalmente, recuperando esas partidas, el texto de la propuesta presidencial para 2020 destina tan solo 29 y 38 millones respectivamente, con el fin de que terminen su actividad en los próximos dos años.

El 30 de junio de 1980 un galerista neoyorkino vio desde su ventana cómo unos obreros se preparaban para demoler el Bonwit Teller Building, un edificio clásico de 1929 diseñado por Warren y Wetmore para construir un edificio de vidrio ahumado de 68 pisos. Y avisó al nuevo propietario del valor de dos bajorrelieves Art-Decó, que habían sido solicitados por el Metropolitan Museum para sus fondos y donados por el nuevo dueño. Pero este joven y ambicioso inversor, despreocupado, dijo más tarde haberse olvidado de detener el destrozo. Las valiosas estatuas fueron derruidas. El nuevo edificio era la rampante Torre Trump (Taylor, 1989). Nadie podrá decir que la sensibilidad del nuevo rector del mundo no era conocida.

\subsection{Conclusión y contexto}

Para finalizar este recorrido, apresurado y voluntariamente parcial, en torno a otras visiones del valor de la cultura, pueden ser útiles algunas precisiones y conclu-

\footnotetext{
${ }^{36}$ Ver https://www.theguardian.com/society/2019/jan/28/councils-say-more-arts-cuts-inevitable-amidrising-social-care-need

${ }_{37}$ Ver https://www.artforum.com/news/trump-tries-to-eliminate-the-nea-and-neh-again-78936
} 
siones sobre el concepto de cultura del que se parte y sobre los posibles escenarios en los que puedan aplicarse las distintas nociones de valor aquí presentadas.

¿De qué hablamos en este texto cuando hablamos de cultura? La mejor manera de delimitar el campo es la de acudir a un diccionario. Y el más detallado de los accesibles es sin duda el de Texeira Coelho (2009), que define el término, citando a Raymond Williams, como el proceso de cultivo de la mente, en su visión científica y contemporánea, o el proceso de cultivo del espíritu, si atendemos a una visión más tradicional. En este marco la cultura es al tiempo un estado mental (o espiritual), al proceso que conduce a ese estado, que incluye lo que llamamos prácticas culturales y los instrumentos o medios de ese proceso, las formas de creación artística y demás vehículos que conforman un estado o un comportamiento colectivo. Pero, sin desdeñar las numerosas subdivisiones posibles de lo cultural (desde la cultura sin centro a la hibridación, la cultura digital, la cultura autónoma, etc., que también quedan definidas en el diccionario), Texeira concluye que el mejor resumen de la idea de cultura, muchas veces despreciado por las políticas culturales, es el que la presenta como «una larga conversación, entre todo lo que es cultura, entre todos los que mueven la cultura, una larga y franca conversación». Esa es en realidad la mejor idea de libertad.

En esta idea se incluyen pues como valores centrales algunos de los propios de la conversación: el desacuerdo, el conflicto inherente a las distintas visiones de lo cultural por las comunidades y su gestión política, el principio de la discrepancia como conductor eficaz de la interculturalidad a través del reconocimiento del Otro y de la búsqueda de formas de convivencia cotidiana en las que la cultura, convertida en política pública, articula nuevas formas de inteligencia colectiva. Y algunas de las versiones plurales de esos valores son las que se han pretendido mostrar en estas páginas.

Buena parte de la percepción del valor de la cultura, en la amplia literatura existente sobre el tema, parece moverse hoy entre dos polos. Por un lado, la ingente producción de análisis académicos cuyo factor motivador es el del valor económico de la cultura y por tanto su conversión en una mercancía más del mercado global, sin función social alguna que no sea la del entretenimiento; y por otro, una también relevante literatura crítica que mezcla la teoría de la Escuela de Frankfurt con el pensamiento postestructuralista francés (Foucault, Deleuze...) y cierto pensamiento radical del populismo europeo y latinoamericano (desde Negri a Badiou, Mouffe o Lazzarato), que convierte a la cultura en una herramienta más de una visión crítica del modelo productivo y un conductor de la lucha antisistema.

En este texto se recogen otras visiones posibles que proponen para ella un papel diferente en las vidas de personas y comunidades, prologando la conversación a la que Teixeira en su definición hace referencia. No hay una sola manera y sí muchas opciones. Hacer de la cultura un conductor transversal más, de entre los que hacen posible mejorar la vida de la gente, requerirá incentivar ese diálogo en múltiples direcciones y reclama de instituciones y personas interesadas la asunción de la voluntad colectiva, profesional y personal necesaria para que pueda ocurrir. 


\section{Referencias bibliográficas}

Adorno, T. (1991). The Culture Industry. London: Routledge.

Badiou, A. (2009). L'Hipothése communiste. Paris: Nouvelles Éditions Lignes.

Baumol, W. J., \& Bowen, W. (1966). Performing Arts, The Economic Dilemma. New York: The Twentieth Century Fund.

Banfield, E. (1984). The Democratic Muse: Visual Arts and the Public Interest. New York: Basic Books Inc.

Baran, P., \& Sweezy, P. (1966). Monopoly Capital. New York: Monthly Review Press.

Barreiro, B. (2013). The right of access to culture. An effective human right for the establishment of consistent cultural policies in Europe in the context of the economic crisis? Revista Española de Relaciones Internacionales, 5, 44-62.

Bataille, G. (1987). La parte maldita precedida de la noción de gasto. Barcelona: Editorial Icaria.

Bataille, G. (2005). El límite de lo útil (fragmentos de una versión abandonada de «La parte maldita»). Madrid: Losada.

Bau-Graves, J. (2005). Cultural Democracy. The Arts, Community \& the Public Purpose. University of Illinois Press.

Bauman, Z. (2002). La cultura como praxis. Barcelona: Paidós.

Belfiore, E. (2012). 'Defensive instrumentalism' and the legacy of new Labour's cultural policies. Cultural Trends, 21(1), 103-111.

Belfiore, E. (2015). 'Impact', 'value' and 'bad economics': Making sense of the problem of value in the arts and humanities. Arts \& Humanities in Higher Education, 14(1), 95-110.

Belfiore, E. (2018). Whose cultural value? Representation, power and creative industries. International Journal of Cultural Policy. https://doi.org/10.1080/10286632.2018.1495713

Bell, D. (1977). Las contradicciones culturales del capitalismo. Madrid: Alianza Editorial.

Benjamín, W. (2013). Obras. Libro V, vol. 1, Obra de los pasajes 1. Madrid: Abada editores

Benjamin, W. (2008). Obras. Libro I vol. 2. Madrid: Abada editores.

Berman, M. (1983). All that is Solid Melts Into Air. The Experience of Modernity. London: Verso.

Blaug, M. (Ed.) (1976). The Economics of the Arts. London: Robertson.

Botting, F. (1998). Bataille. London: Blackwell.

Brockman, J. (Ed.) (2012). Cultura. Barcelona: Crítica.

Caves, R. (2000). Creative Industries. Contracts between Art and Commerce. Cambridge Mass.: Harvard University Press.

Cummings, M. C. Jr., \& Katz, R. S. (1987). The Patron State. Government and the Arts in Europe, North America and Japan. Oxford University Press.

Cummings, M. C., Jr. \& Schuster, J. M. (Eds.) (1989). Who's to pay for the Arts. The International Search for Models of Support. New York: ACA Books.

Dekker, E. (2017). The Economic De-legitimization and Legitimization of Arts Policies 19701985, en J. Bek-Thomsen, C. O. Christiansen, S. G. Jacobsen y M. Thorup (Eds.), History of Economic Rationalities: Economic Reasoning as Knowledge and Practice Authority, cap. 12, 113-120. Ethical Economy (Studies in Economic Ethics and Philosophy), 54. Cham: Springer Publishing Company. https://doi.org/10.1007/978-3-319-52815-1_12.

Deleuze, G. y Guattari, F. (1994). Mil mesetas. Capitalismo y esquizofrenia. Valencia: Ed. Pretextos. 
Dubin, S. (1987). Bureaucratizing the Muse. Public Funds and the Cultural Worker. Chicago: The University of Chicago Press.

Eagleton, T. (2001). La idea de cultura. Barcelona: Paidós.

Eagleton, T. (2017). Cultura. Barcelona: Taurus.

Fisher, M. (2009). Capitalist Realism. Is there no alternative? London: Zero Books

Foucault, M. (2009). Nacimiento de la biopolitica. Madrid: Akal.

Frey, B. S., \& Pommerehne, W. (1989). Muses and Markets. Explorations in the Economics of the Arts. Oxford: Blackwell.

Frey, B. S. (2000). La economía del Arte. Colección Estudios Económicos 18. Servicio de Estudios de «la Caixa».

Frey, B. S., \& Stutzer, A. (2002). Happiness and economics. How the economy and institutions affect well-being. Princeton, NJ: Princeton University Press.

Frey, B. S. (2008). Happiness: A Revolution in Economics. MIT Press.

Frey, B. S. (2018). Economics of Happiness. Springer International Publishing.

Frey, B. S. (2019). Economics of Art and Culture. Springer International Publishing.

García Canclini, N. (2010). La sociedad sin relato. Antropología y estética de la inminencia. Buenos Aires: Katz Editores.

Gellner, E. (1983). Nations and Nationalism. Oxford: Blackwell. Gorz, A. (1989). Critique of Economic Reason. London, New York: Verso.

Grampp, W. (1989). Pricing the Priceless. Art, Artists and Economics. New York: Basic Books Inc.

Greemberg, C. (1961). Avant Garde and Kitsch. En Art and Culture: Critical Essays. 12-14. Boston: Beacon Press.

Groys, B. (2005). Sobre los nuevo. Ensayo de una economía cultural. Valencia: Ed. Pretextos.

Groys, B. (2008). Bajo sospecha: Una fenomenología de los medios. Valencia: Ed. Pretextos. Han, B. (2017). La expulsión de lo distinto. Barcelona: Herder.

Hedsmondhalgh, D. (2012). The Cultural Industries. London: Sage.

Heilbrun, J., \& Gray, Ch. (1993). The Economics of Art and Culture. An American Perspective. New York: Cambridge University Press.

Horne, D. (1986). The Public Culture. London, Sydney, Dover: The Pluto Press.

Jakubowski, A. (2016). Cultural Rights as Collective Rights: An International Law Perspective. Leiden: Koninklijke Brill.

Jameson, F. (1992). Signatures of the visible. London: Routledge.

Jeffers, A., \& Moriarty, J. (Eds.) (2017). Culture, Democracy and the Right to Make Art: The British Community Arts Movement. London: Bloomsbury.

Kant, I. (1999). Crítica del Juicio. Madrid: Espasa Calpe.

Keynes (1930). Posibilidades económicas de nuestros nietos. Recuperado de https://arquitecturacontable.wordpress.com/2016/10/23/posibilidades-economicas-denuestros-nietos-j-m-keynes-1930/

Klagge, J. (1986). Marx's Realms of 'Freedom' and 'Necessity'. Canadian Journal of Philosophy, 16 (4), 769-777. Recuperado de http://www.jstor.org/stable/40231502

Klamer, A. (1996). The Value of Culture: On the relationship between economics and arts. Amsterdan University Press. Recuperado de https://www.google.com/search?q=arjo+kla mer+the+value+of+culture \&rlz=1C1CHBF_esES848ES848\&oq=Arjo+Klamer\&aqs= chrome.4.69i57j35i39j014.11123j1j8\&sourceid=chrome \&ie=UTF-8 
Land, N. (1992). The thirst for Annihilation: Georges Bataille and Virulent Nihilism. London: Routledge.

Lazzarato, M. (2006). Por una política menor. Madrid: Traficantes de Sueños. Longino (2014). De lo Sublime. Barcelona: Acantilado.

Lyotard, J. (1991). Leçons sur l'analytique du sublime. Paris: Galilée.

Lyotard, J. (1984). The Sublime and the Avant-Garde. Artforum, 4, 36-43.

Lyotard, J. (1997). El entusiasmo. Crítica kantiana de la historia. Barcelona: Gedisa.

Lyotard, J. (2009). La postmodernidad (explicada a los niños). Barcelona: Gedisa.

Mauss, M. (2009). Ensayo sobre el don. Forma y función del intercambio en las sociedades arcaicas. Buenos Aires: Katz Editores.

May, A. (2018). From Bataille to Badiou. Lignes: The Preservation of Radical French Thought 1987-2017. Liverpool: Liverpool University Press.

McGuigan, J. (1996). Culture and the Public Sphere. London: Routledge.

McGuigan, J. (2004). Rethinking Cultural Policy. London: Open University Press.

Galleti, M., \& Bayne, R. (Eds.) (2018). Bataille and Heterology. Theory, Culture and Society, 35, 4-5.

Miège, B. (1989). The Capitalization of Cultural Production. New York: International General.

Miller, T., \& Yudice, G. (2004). Política cultural. Barcelona: Gedisa.

Mouffe, Ch. (2007). Prácticas artísticas y democracia agonística. Barcelona: MACBA y UAB.

Moulier Boutang,Y. et al. (2004). Capitalismo cognitivo, propiedad intelectual y creación colectiva. Madrid: Traficantes de Sueños.

Negri, T. (2016). Arte y multitudo. Madrid: Trotta Editorial.

Ordine, N. (2013). La utilidad de lo inútil. Manifiesto. Barcelona: Acantilado.

Peacock, A., \& Rizzo, I. (Eds.) (1993). Cultural Economics and Cultural Policy. Dordrecht, Boston, London: Kluwert Academic Publishing.

Pick, J. (1988). The Arts in a State. A study of Government Arts Policies from Ancient Greece to the Present. Bristol: Bristol Classical Press.

Plotnitsky, A. (1993). Reconfigurations: Critical Theory and General Economy. Miami: University Press of Florida.

Prieto, J. (1992). Cultura, culturas y constitución. Madrid: Centro de Estudios Políticos y Constitucionales.

Richardson, M. (1994). Georges Bataille. London: Routledge.

Sloterdijk, P. (2002). El desprecio de las masas. Ensayo sobre las luchas culturales de la sociedad moderna. Valencia: Pretextos.

Taylor, J. (1989). El circo de la ambición: la cultura del dinero y del poder. Anagrama.

Teixeira Coelho (2009). Diccionario crítico de política cultural. Barcelona: Gedisa.

Throsby, D. (1999). Cultural Capital. Journal of Cultural Economics. https://doi.org/ 10.1023/A: 1007543313370

Throsby, D. (2001). Economía y Cultura. Madrid: Akal.

Throsby, D. (2010). The Economics of Cultural Policy. New York: Cambridge University Press.

Throsby, D., \& Withers, G. (1976). The Economics of the Performing Arts. Melbourne: Edward Arnold.

Tolila, P. (2007). Cultura e economía. Sao Paulo: Editora Iluminuras.

Towse, R. (Ed.) (2005). Manual de economía de la cultura. Madrid: Fundación Autor.

Towse, R. (Ed.) (2011). A Handbook of Cultural Economics. Cheltenham: Edward Elgar Publishing. 
Towse, R. (2014). Advanced Introduction to Cultural Economics. Cheltenham: Edward Elgar Publishing.

Williams, R. (2008). Historia y cultura común. Madrid: Los Libros de la Catarata.

Wright, C. (2013). Against Flourishing en Health, Culture and Society, 5(1). http://dx.doi. org/10.5195/hcs.2013.151

Wu, C. (2007). Privatizar la cultura. La intervención empresarial en el mundo del arte desde la década de 1980. Madrid: Akal.

Wallach, G., Bradford, G., \& Gary, M. (Eds.) (2000). The Politics of Culture. New York: The New Press.

Zallo, R. (2018). Desenredando la economía de la cultura. Periférica Internacional. Revista para el Análisis de la Cultura y el Territorio, 18. http://dx.doi.org/10.25267/Periferica. 2017.i18.07 